\title{
Posmodernismos y feminismos: diálogos, coincidencias y resistencias
}

\author{
Rosalva Aída Hernández Castillo
}

\begin{abstract}
A partir de una lectura crítica del feminismo posmoderno anglosajón, este artículo se propone recuperar aquellas propuestas metodológicas y epistemológicas que puedan resultar útiles a quienes, desde América Latina, están cuestionando los paradigmas etnocéntricos del positivismo occidental. Propiciar el diálogo entre teóricas feministas, defensoras y detractoras del posmodernismo, le permite a la autora acercarse a los debates en torno al carácter patriarcal de la ciencia occidental y a las búsquedas epistemológicas y políticas emprendidas desde diferentes feminismos para construir un conocimiento no etnocéntrico y una práctica feminista que incorpore la diversidad.

From a critical reading of Anglo-Saxon postmodern feminism, this article seeks to recover those methodological and epistemological proposals which may prove useful to Latin Americans who are questioning ethnocentric paradigms of Western positivism. The fact of having theoretical feminists, defenders and detractors of postmodernism, exchange ideas enables the author to approach the debates on the patriarchal nature of Western science and the epistemological and political quests undertaken from different angles of feminism to construct a non-ethnocentric knowledge and feminist practice which includes diversity.
\end{abstract}

ROSALVA AÍDA HERNÁNDEZ CASTILLO: CIESAS-México.

Desacatos, núm. 13, invierno 2003, pp. 107-121. 
Because I am in all cultures at the same time, alma entre dos mundos, tres cuatro, me zumba la cabeza con lo contradictorio.

Estoy norteada por las voces que me hablan simultáneamente.

\section{FRONTERAS/BÚSQUEDAS/DIÁLOGOS}

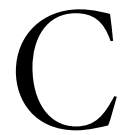

on estas palabras Gloria Anzaldúa describe lo que ella llama las nuevas identidades de frontera o border identities. La poeta y crítica literaria chicana reivindica la identidad de una "nueva mestiza" que cuestiona cualquier criterio de autenticidad y purismo cultural, que nos recuerda que no hay nada estático, pues incluso las "tradiciones milenarias" se han vuelto milenarias a partir de que alguien las resignifica y las reivindica como tales. Las identidades de frontera no sólo confrontan las tradiciones culturales, sino la manera misma en que se define "la tradición": 108
Soy un amasamiento, soy el acto mismo de amasar, de unir

sexistas del género del movimiento feminista. A partir de su propia experiencia, nos muestra las limitaciones de aquellas políticas de identidad que parten de un criterio de autenticidad y exclusión. No se propone hacer una teoría general de la identidad, ni plantear que las identidades siempre se viven como múltiples y contradictorias, simplemente da cuenta de que en el nuevo contexto global hay muchos sujetos que, como ella, viven sus identidades como un amasamiento y a quienes les "zumba la cabeza con lo contradictorio".

Borderlands/La Frontera... no es un testimonio celebratorio de la posmodernidad, sino un llamado, desde la experiencia personal, a buscar nuevas herramientas teóricas que den cuenta de la realidad de estos actores sociales, para poder construir nuevas estrategias políticas que respondan a sus necesidades. A diferencia de otros autores posmodernos que nos describen un mundo de fronteras porosas en donde todas las culturas pueden entrar festivamente en contacto, Anzaldúa plasma en su poesía y en sus ensayos la existencia de fronteras militarizadas donde el poder y la dominación marcan el contexto en el que se dan los encuentros culturales.

La nueva mestiza no está sola en esta búsqueda política y epistemológica, otras feministas desde distintas experiencias y desde diferentes partes del mundo también están confrontando las visiones esencialistas de "la mujer" que reivindican algunas políticas de la diferencia, al igual que las ficciones del humanismo en las que se basa la política de la igualdad. ${ }^{2}$ En la tarea de develar y analizar las relaciones de desigualdad entre hombres y mujeres y de buscar vías para construir una vida más digna para las segundas, las feministas nos hemos encontrado con el dilema de optar entre políticas de la diferencia que muchas veces reifican estereotipos sobre lo femenino y lo masculino, o por políticas de la igualdad que no reconocen las estructuras de dominación.

ta, Anzaldúa se rebela ante el machismo del nacionalismo chicano y ante sus definiciones limitadas y "disciplinarias" de la tradición. A la vez, como chicana, confronta el etnocentrismo y el clasismo del movimiento feminista anglosajón, y como lesbiana, cuestiona tanto la homofobia del nacionalismo chicano como las visiones hetero-

\footnotetext{
${ }^{1}$ Anzaldúa, 1987: 81, traducción mía.
}

2 En este tipo de búsquedas se encuentran los trabajos de feministas de color en Estados Unidos como Trinh Min-ha (1988), Norma Alarcón (1990), Michel Wallace (1990) y Bell Hooks (1988); en los de feministas de la India como Chandra Mohanty (1991), Lata Mani (1999) y Vasanth Kannabiran (1997), y en los de feministas africanas como Ayesha Mei-Tje Imam (1997) y Amina Mamma (1997), entre otras muchas. 


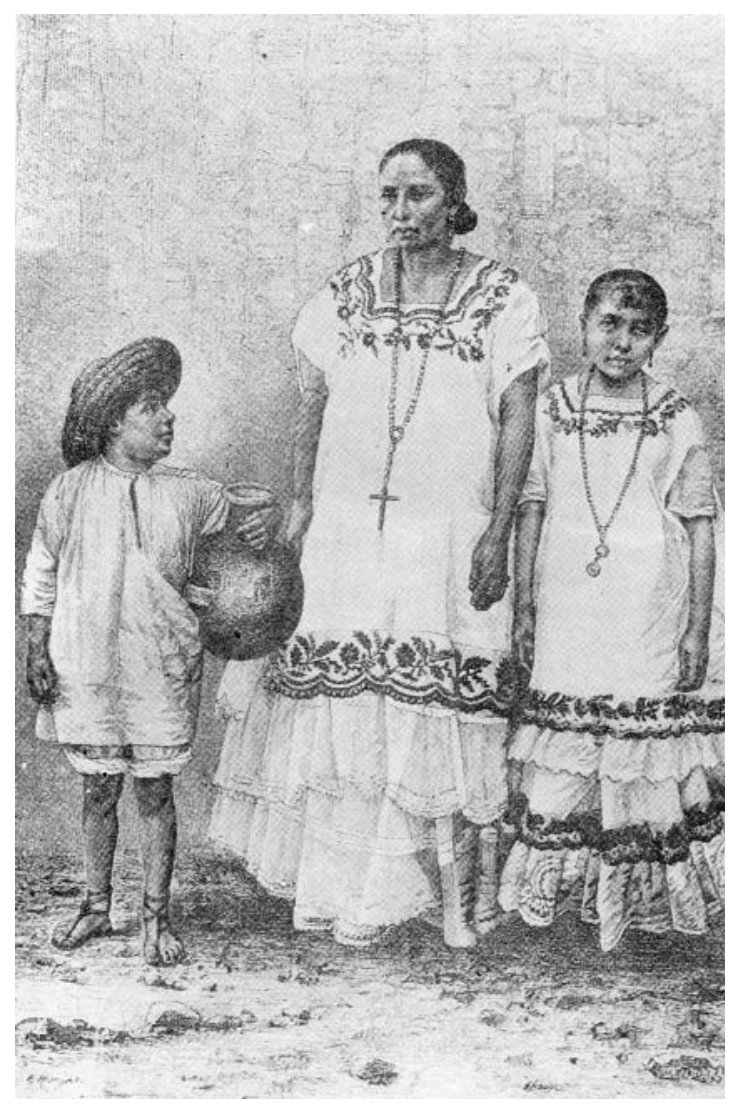

Mujeres y niño mestizos.

Como una reacción ante la desvalorización de la esfera doméstica o la descalificación de prácticas consideradas como femeninas, algunas feministas han optado por un feminismo de la diferencia que tiende a idealizar prácticas como la maternidad y la lactancia o cualidades como la emotividad, que terminan por convertirse en nuestra propia camisa de fuerza (Einstein y Jardine, eds., 1989). En un esfuerzo por construir un sentido de colectividad, un "nosotras", se han esencializado identidades excluyendo la diferencia al interior de las propias mujeres.

En sentido opuesto, otras feministas han decidido jugar el juego en un "campo marcado", asumiendo las reglas de las instituciones patriarcales para lograr la igualdad, utilizando el discurso de objetividad y racionalidad, para descalificar el sexismo como "irracional" y combatir los "prejuicios" masculinos (Rossi A., 1970).
Ante este dilema algunas feministas han encontrado en los autores posmodernos algunas pistas para romper con las dicotomías igualdad-diferencia, racionalidadirracionalidad, objetividad-subjetividad. En la búsqueda de nuevas estrategias epistemológicas y nuevas formas de concebir al sujeto, se ha establecido un diálogo crítico con el posmodernismo retomando algunas de sus propuestas deconstruccionistas para develar las redes de poder que ocultan la aparente objetividad del conocimiento científico. Algunas autoras han reivindicado la existencia de un feminismo posmoderno y otras han preferido tomar en cuenta algunas lecciones de esta corriente teórica para construir un nuevo tipo de feminismo que sin definirse como posmoderno hace del constructivismo histórico una herramienta metodológica fundamental.

En este artículo me propongo reconstruir algunos de los diálogos implícitos y explícitos que se han dado en las últimas dos décadas entre los teóricos posmodernos y las teóricas feministas, y a partir del análisis de estos encuentros y desencuentros, desarrollar algunas reflexiones sobre los aportes que pueden hacer estas búsquedas a nuestros propios cuestionamientos desde los feminismos latinoamericanos.

\section{TEORIZANDO DESDEY SOBRE LA POSMODERNIDAD}

Cuando señalo que el posmodernismo ha tenido una importante influencia en la epistemología feminista de las últimas décadas, me refiero al posmodernismo en dos sentidos, como momento histórico y como corriente teórica. Considero importante diferenciar las aproximaciones de quienes han teorizado sobre la posmodernidad como una lógica cultural que corresponde a un momento específico del desarrollo capitalista (Harvey, 1990; Jameson, 1990; Larsen, 1995), de quienes han teorizado desde la posmodernidad como una perspectiva teórica que se propone romper con valores y formas de conocimiento heredadas de la Ilustración (Foucault, 1980; Lyotard, 1993 [1984]; Rortry, 1979).

El concepto de posmodernismo fue retomado por ambas corrientes de la arquitectura, en donde se usa para 
describir un estilo de construcción que mezcla elementos estilísticos de diferentes momentos históricos en un pastiche o bricolage arquitectónico (Colquhoun, 1985). El uso de este concepto se popularizó primero en las artes gráficas, después en la literatura y en las ciencias sociales, cambiando en cada ámbito el sentido original de hibridez cultural o mezcla de estilos por otro más complejo que hacía referencia a la ruptura con cualquier tipo de estructura de conocimiento. En las ciencias sociales el posmodernismo se convirtió en sinónimo de posestructuralismo.

Sin pretender homogeneizar las posturas de todos los que teorizan sobre la posmodernidad y de quienes escriben desde la posmodernidad, es necesario resaltar la existencia de una tendencia entre ambas posiciones a descalificarse mutuamente, asumiendo los primeros que el rechazo de los posmodernos a las metateorías y al análisis sistémico es un ejemplo más de la enajenación que produce esta nueva etapa de capitalismo globalizado; mientras que los segundos ven a los teóricos neomarxistas como atrapados en las falasias de la Ilustración que los mantie-
Ambas corrientes coinciden en que han sucedido transformaciones históricas que influyen en nuestras formas de conocer. Aunque no existe una definición consensada de lo que implica el posmodernismo, algunos de los rasgos que se mencionan como característicos de este momento histórico son: 1) la fractura de los ideales que regularon el proceso civilizatorio de la modernidad occidental —historia, progreso, sujeto, entre otros—; 2) la diversificación de los signos y la multiplicidad de voces y significados; 3 ) el abandono de las certidumbres y la aceptación de los conocimientos parciales y relativos; 4) la hegemonía de los medios masivos de comunicación a través de imágenes cuya espacialidad y temporalidad hacen perder la textura y la densidad histórica.

Según Frederic Jameson y David Harvey, la economía política nos puede ayudar a situar estos cambios dentro de una nueva lógica cultural del capitalismo. La fragmentación de los procesos productivos para integrar una línea de ensamble global, como ocurre con la creación de la maquila y la subcontratación a escala mundial, ha tenido como contraparte, a nivel cultural, una fragmenta- ción de los imaginarios colectivos, una nueva forma de enajenación que imposibilita a los actores sociales ver las vinculaciones entre los procesos locales. ${ }^{3}$ Harvey habla de la transición de un modelo fordista, en el que los procesos productivos se centraban en la fábrica y la vida social de los obreros se desarrollaba alrededor de la misma, a un modelo posfordista de acumulación flexible, en el que las maquilas no crean especialización y se abren y cierran de un día para otro, dificultando la organización de la fuerza laboral (Harvey, 1990: 121-189). Estos cambios en los procesos productivos, aunados a los cambios tecnológicos que han facilitado el movimiento de gente e información, han producido una compresión espaciotemporal que afecta la manera en que los sujetos se imaginan a sí mismos e imaginan su relación con el territorio y la comunidad. Para algunos neomarxistas este sujeto enajenado, con incapacidad para ver su lugar en el proceso productivo y en las estructuras de dominación, es el nuevo sujeto posmoderno que reivindican políticamente los posestructuralistas.

Edward Said coincide con Harvey y Jameson en que el posmodernismo no es una etapa situada "más alla de las ideologías", sino un momento confuso de movimiento de capital y trabajo a nivel global y de rápidas transformaciones y readaptaciones ideológicas (Said, 1987). Sin embargo, nos recuerda que este proceso no se está viviendo de igual forma en todas las partes del mundo y que en muchos sentidos expresa más bien

\footnotetext{
las ansiedades, obsesiones y el hastío de una reducida y privilegiada fracción de clase en Occidente, que ignora el hecho de que en los tiempos actuales se ha dado un resurgimiento de nociones como tradición y autenticidad, y un regreso de la religión, sobre todo en su forma fundamentalista más anti-posmoderna. Por lo que es necesario separar el posmodernismo, como aproximación intelectual, de la época posmoderna, un término descriptivo para referirnos al periodo contemporáneo que aparentemente ha borrado las concepciones modernistas de cambio evolutivo. ${ }^{4}$
}

\footnotetext{
${ }^{3}$ Para un desarrollo más extenso del análisis del posmodernismo como lógica cultural del capitalismo tardío, desarrollada por Frederic Jameson y de sus propuestas políticas para enfrentar este momento histórico a través de mapas cognitivos, véase Hernández Castillo, 1994. ${ }^{4}$ Said, citado por Di Leonardo, 1991: 26.
} 


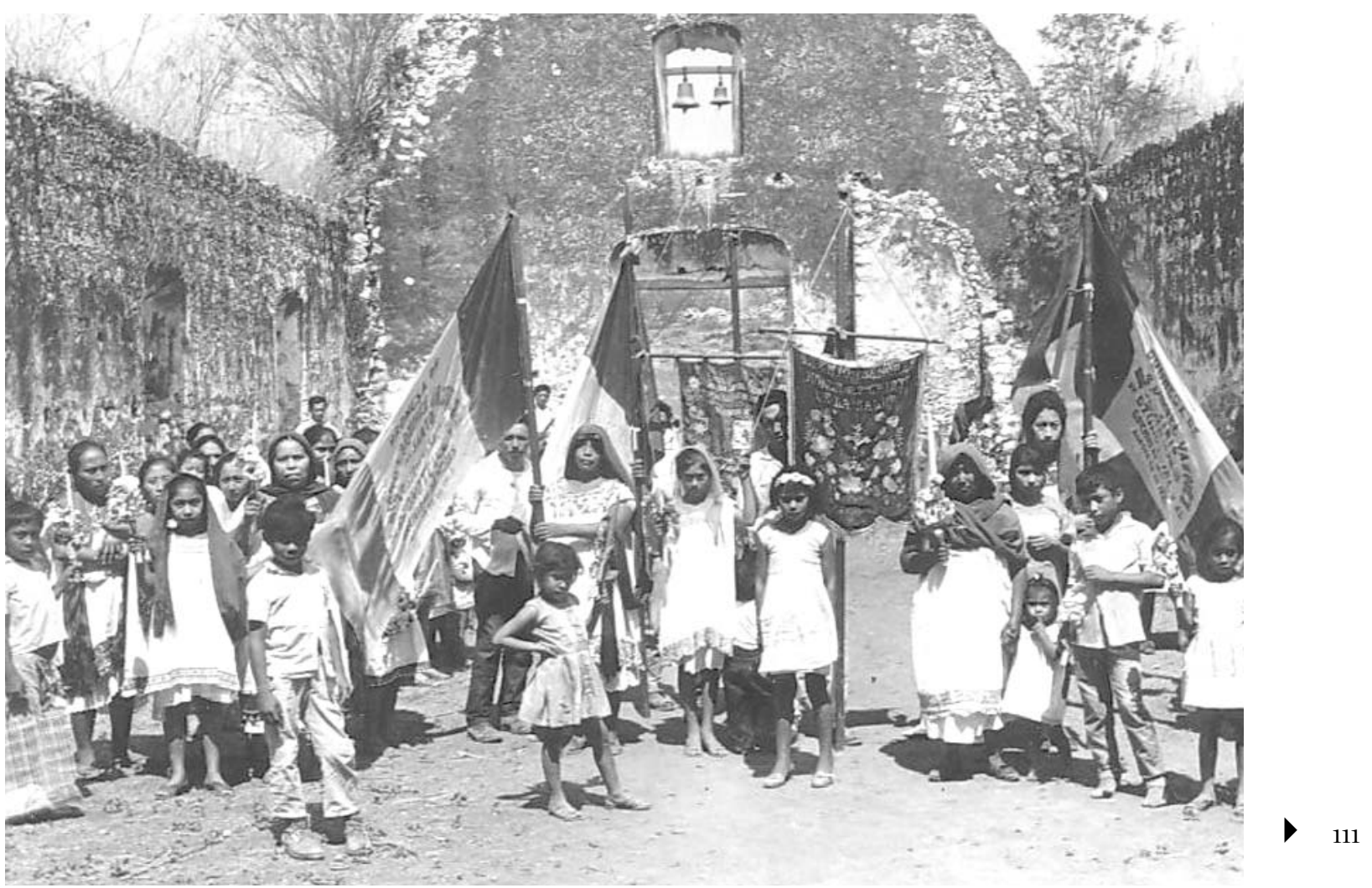

Gremio de Dzonotchel, parroquia de Peto, 1960 / Archivo personal de los RRPP de Maryholl.

Por su lado, los teóricos posestructuralistas consideran a estos análisis de la posmodernidad como parte de las metateorías que se aferran a un concepto de racionalidad y verdad que se encuentra en crisis. Jean Francois Lyotard es uno de los primeros intelectuales que se autodefine como posmoderno e introduce el término en su libro clásico La condición posmoderna (1993 [1984]). Para él, posmodernismo es la condición general de la civilización occidental, en la cual las "grandes narrativas de legitimación" pierden credibilidad. Se refiere al fin de las metanarrativas, a la crisis de la filosofía surgida de la Ilustración que habla de un desarrollo progresivo de la razón y la libertad. Considerado como el ejemplo del relativismo extremo, Lyotard no cree que exista ningún espacio de donde se pueda legitimar el conocimiento o la práctica política, sólo una multiplicidad de espacios de legitimación, locales e inmanentes, y una multiplicidad de pers- pectivas de lo que es verdadero y justo, lo que él llama una "multiplicidad de justicias" (justice of multiplicities) (Lyotard y Thebaud, 1987).

Michel Foucault, por su parte, se encargó de mostrarnos cómo los espacios de legitimación de la ciencia se convirtieron en espacios de poder a partir de los cuales se disciplina y normaliza el comportamiento social (Foucault, 1980, 1992, 1995). Mediante el análisis de los elementos de poder en el conocimiento científico y en otras prácticas modernas como la clínica y la legalidad, estos autores posmodernos extendieron el espacio del poder más allá de la economía y el Estado, espacios tradicionales en donde los marxistas habían ubicado sus análisis del poder y la dominación.

Los trabajos de los autores que se autodefinen como posmodernos cuestionan la existencia de un sujeto social estable y coherente capaz de razonar y de tener acceso 


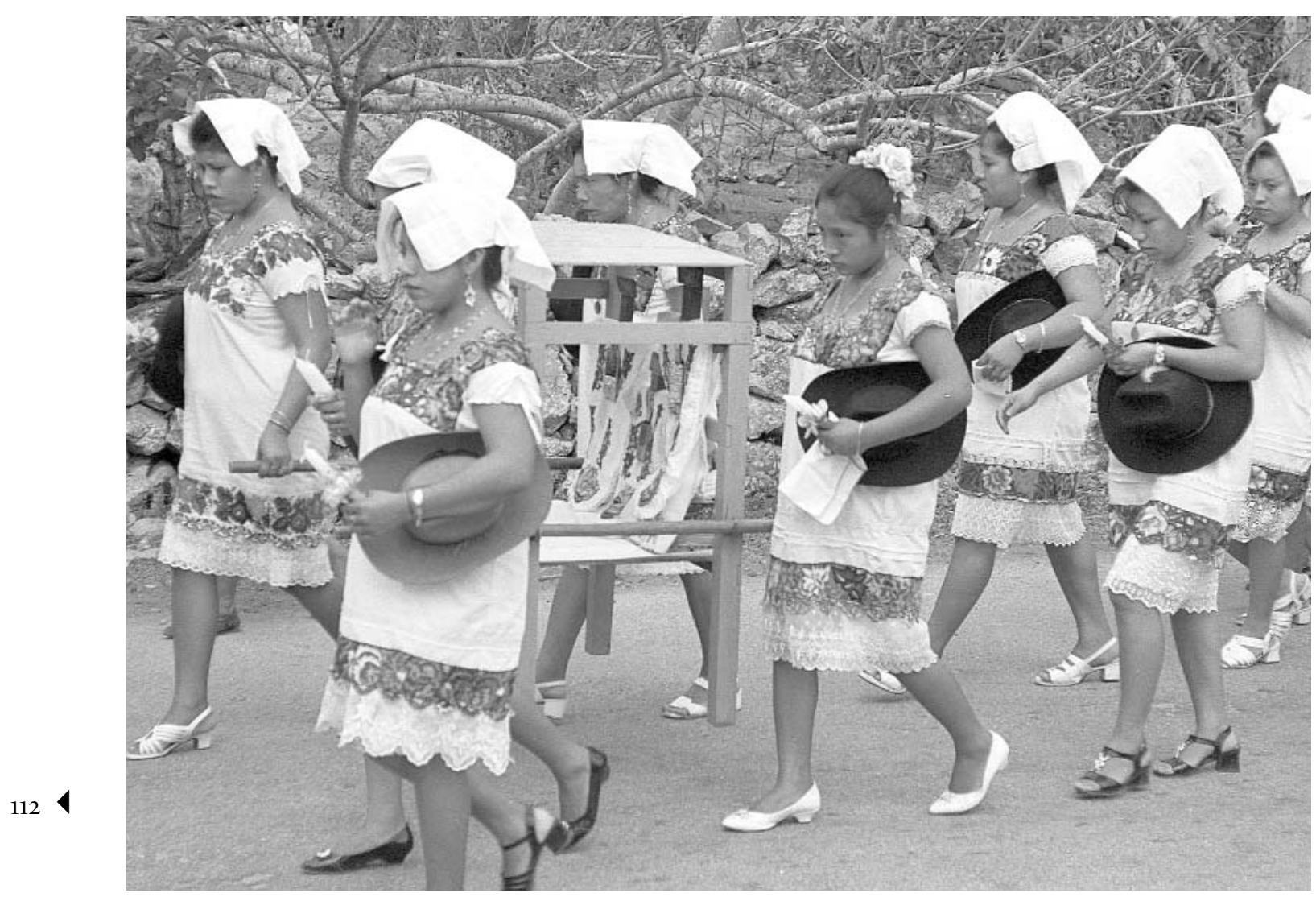

Procesión al santuario de Xocén. Las “vaqueras” llevan una pequeña imagen de la cruz enarbolada en la guerra de castas / Christian Rasmussen.

a las leyes de la naturaleza y de una racionalidad que a través de la ciencia pueda proporcionar un conocimiento objetivo y verdadero. Con estos cuestionamientos desestabilizan no sólo el poder de aquellos que bajo la máscara de la objetividad venían imponiendo su verdad sobre el mundo y las relaciones sociales, sino también el de aquellas y aquellos que habían encontrado en conceptos como justicia, igualdad y libertad un asidero para confrontar los discursos del poder.

Estas dos perspectivas sobre y desde la posmodernidad han influido en las búsquedas epistemológicas de las feministas, alimentando sus diálogos y resistencias hacia las teorías posmodernas.

Desde el feminismo, Donna Haraway (1990) teoriza sobre y desde la posmodernidad. Es decir, al igual que los neomarxistas reconoce al posmodernismo como una perspectiva situada históricamente, producto de cambios en los procesos sociales que han afectado no sólo la organización de la fuerza de trabajo, sino también las estructuras familiares y comunitarias. Reconoce el surgimiento de nuevas subjetividades que se crean y se recrean en el marco de nuevas formas de dominación, las cuales incluyen no sólo los procesos de trabajo o las instituciones del Estado, sino también las nuevas redes y tecnologías de la comunicación. Pero a diferencia de Jameson o Harvey, no se ubica en un lugar privilegiado para analizar esos procesos, no los ve desde fuera como el tradicional narrador omnisciente, al contrario, se reconoce como parte de los mismos y desde este nuevo espacio contradictorio se propone encontrar alternativas para conocer y transformar la realidad (objetivo bastante moderno, por cierto, y vinculado a la epistemología marxista). Como alter- 
nativa al objetivismo de la ciencia patriarcal, Haraway propone un conocimiento situado (situated knowledge) que reconoce el contexto histórico y social desde el cual se percibe la realidad, pero que a la vez no renuncia a la posibilidad de conocer, ni relativiza el valor ético y explicativo de cualquier conocimiento. La autora plantea:

\begin{abstract}
La alternativa al relativismo son los conocimientos parciales, localizables y críticos que admiten la posibilidad de conexiones llamadas solidaridad en la política y conversaciones compartidas en la epistemología... El relativismo es el perfecto espejo gemelo de la totalización, ambos son "trucos divinos" que prometen, al mismo tiempo y en su totalidad, la visión desde todas las posiciones y desde ningún lugar, mitos comunes en la retórica que rodea la ciencia. Pero es precisamente en la política y en la epistemología de las perspectivas parciales donde se encuentra la posibilidad de una búsqueda objetiva, sostenida y racional. ${ }^{5}$
\end{abstract}

Para Haraway, a pesar de la complejidad de las formas de dominación en el actual momento histórico, no todo es pesimismo; esta nueva etapa abre a la vez nuevos espacios de resistencia. Se trata, pues, de un momento histórico con elementos positivos y negativos. Para hablar de los valores mezclados de esta época utiliza la metáfora de la cyborg (Haraway, 1990). Una cyborg es un fenómeno que viola ciertas distinciones antes dominantes, especialmente aquellas establecidas entre humanos y animales, humanos y máquinas, mentes y cuerpos, materialismo e idealismo. La cyborg rechaza las antiguas esperanzas en la unidad y la totalidad que se expresaban en la idea de una fuerza de trabajo liberada, la comunidad como familia, lo femenino como divinidad... Este nuevo sujeto histórico no necesita crear mitos de origen de un pasado idílico: "La escritura de la cyborg no necesita tratar del había una vez un tiempo de integridad, antes del lenguaje, antes de la escritura, antes del hombre. La escritura de la cyborg es acerca del poder por razón de sobrevivencia, no en base a una inocencia original, sino buscando las herramientas para marcar al mundo que alguna vez la aisló en la otredad" (p. 218); su identidad no necesita ser armónica, ni basada en la autenticidad:

\footnotetext{
${ }^{5}$ Haraway, 1991: 329, traduccción mía.
}

"El cuerpo de la cyborg no es inocente, no nació en el edén, no busca una identidad unificada y no genera dualismos antagónicos interminables (o hasta el fin del mundo) y asume la ironía como un hecho" (p. 217). En un momento histórico en el que la dominación se ejerce a través de imágenes e información, el lenguaje y la escritura se convierten en una herramientas fundamental: " $\mathrm{La}$ escritura es la principal tecnología de la cyborg... la forma de hacer política de la cyborg es la lucha por el lenguaje y la lucha contra la comunicación perfecta, contra ese código que asume que es capaz de traducir perfectamente todos los significados" (p. 218). La cyborg nos recuerda en mucho a la nueva mestiza descrita por Gloria Anzaldúa; de hecho, Haraway propone que la identidad de las "mujeres de color" es una identidad de cyborg, pues transgrede diversas fronteras y confronta perspectivas esencialistas de la identidad. ${ }^{6}$

Su propuesta es romper con las formas de hacer política enraizadas en la identidad compartida o en los partidos políticos mediante una acción que parta del reconocimiento de los aspectos múltiples y contradictorios de nuestras identidades individuales y colectivas. A diferencia de varios teóricos posmodernos, el descentramiento del sujeto y el reconocimiento de la crisis en los discursos totalizadores no lleva Haraway a la desmovilización política, sino a buscar formas creativas para enfrentar este momento histórico.

Este compromiso con la transformación de la realidad y esta necesidad de mantener una resistencia activa a las distintas formas de dominación es lo que ha diferenciado a las feministas posestructuralistas de los teóricos posmodernos. En las palabras de Nancy Fraser y Linda J. Nicholson: "Aquellas mujeres cuyas teorizaciones tenían el propósito de aportar algo a la lucha contra el sexismo no iban a abandonar tan fácilmente sus herramientas políticas sólo como resultado de los debates intramuros entre profesionales de la filosofia" (1990: 26).

\footnotetext{
${ }^{6}$ Esta afirmación ha causado distintas reacciones entre las feministas de color que han sentido que la visión idealizada de ellas que hace Haraway es otra forma de colonialismo discursivo. Para una crítica a la metáfora de la cyborg desde el feminismo chicano, véase Moya, 1997.
} 


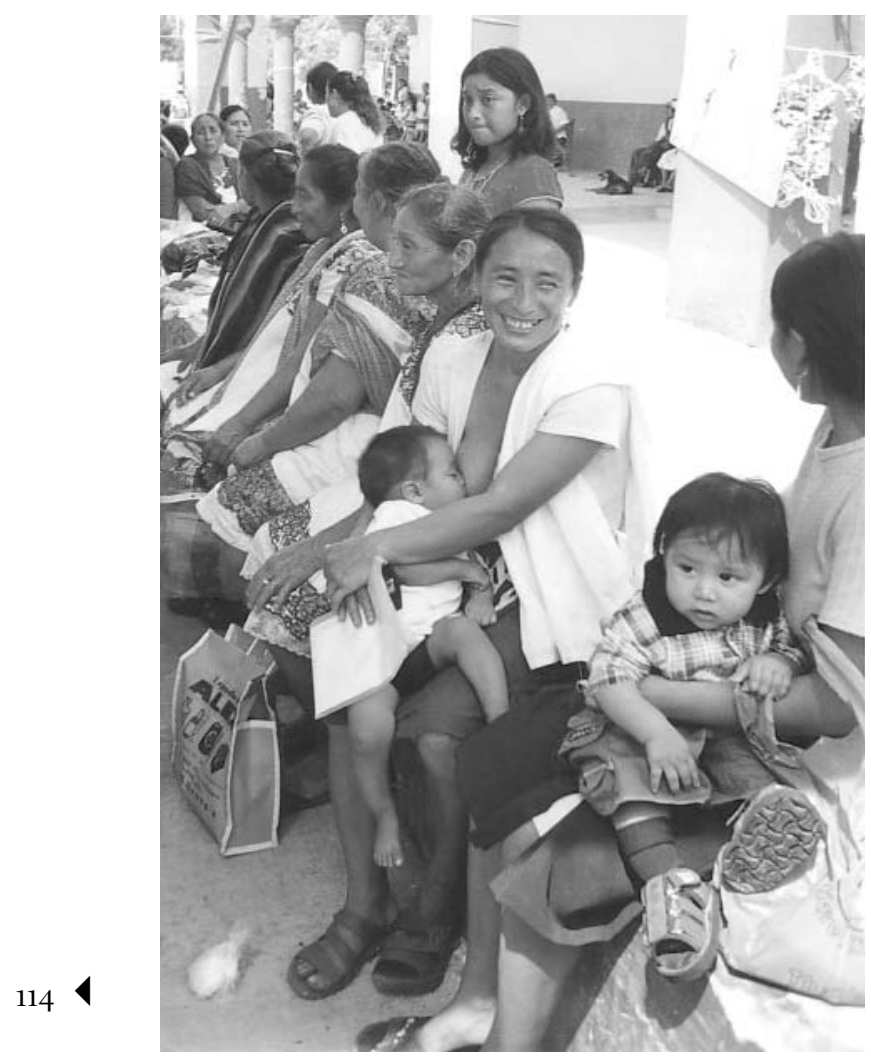

Mujer amamantando. Tiholop, 2003 / Jesús Lizama.

\section{FEMINISMOSY MODERNIDAD}

Pero el "había una vez un tiempo de integridad" al que renuncia la cyborg no es sólo la meta-narrativa de la ciencia patriarcal, sino parte integral de la historia del feminismo occidental y de sus búsquedas de "la causa" de la opresión de la mujer. La historia del feminismo académico está marcada por la tensión constante entre aquellas corrientes que empujan a crear meta-narrativas como formas de teorizar y otras que forzan a situar e historizar los análisis. La búsqueda de una herramienta explicativa de las desigualdades de género válida para cualquier contexto ha sido una constante en la producción académica feminista. Desde distintas perspectivas, las principales teóricas del feminismo occidental han buscado algún tipo de práctica humana que se pueda encontrar en todas las sociedades y que tenga poder explicativo con respec- to a las desigualdades entre hombres y mujeres. Shulamith Firestone (1970) reivindicaba la biología como el centro de la opresión de la mujer; Michelle Zimbalist Rosaldo (1974), la separación entre lo público-masculino y lo privado-femenino; Nancy Chodorow (1978), la maternidad como esencial en la construcción de una identidad de género, por poner sólo algunos ejemplos.

La lealtad de las feministas a los valores y mitos de la modernidad es explicada por Jane Flax en los siguientes términos:

\begin{abstract}
Filósofos de la Ilustración, como Kant, no pretendían incluir a las mujeres entre aquella población que consideraban capaz de liberarse de las formas tradicionales de autoridad; sin embargo, es comprensible que aquellas personas que han sido definidas como incapaces de auto-emanciparse, insistan en que conceptos como verdad objetiva y acceso al progreso a través del descubrimiento científico incluyan y sean aplicables a las capacidades y experiencias tanto de hombres como de mujeres. También resulta atractivo para los que han sido excluidos el creer que la razón va a triunfar y que quienes proclaman ideas como la objetividad y la verdad científica van a responder positivamente ante argumentos racionales. Si no existen bases objetivas para distinguir entre creencias verdaderas y falsas, parecería que sólo el poder puede determinar cuáles argumentos serán considerados como verdaderos y cuáles no. Esta es una perspectiva aterradora para aquellos y aquellas que carecen del poder (o son oprimidos por el poder de otro). ${ }^{7}$
\end{abstract}

Así, desde el empiricismo, algunas feministas se dieron a la tarea de tratar de confrontar la "mala ciencia" con un tipo de ciencia que no tuviera prejuicios sexistas y androcentristas, asumiendo que mediante una aplicación correcta del método científico se podrían corregir estos errores.

Otras, sin embargo, optaron por rechazar por completo los conceptos de objetividad y verdad científica, reconociendo la estructura de dominación de género que se oculta bajo la fachada de neutralidad y universalismo. Al empiricismo y a la aparente objetividad del método científico, estas feministas opusieron la denominada epistemología del posicionamiento o punto de vista (stand point

\footnotetext{
7 Flax, 1990: 42, traducción mía.
} 
theory). Estas perspectivas asumen que si el conocimiento está fundamentado en la experiencia, la ciencia occidental sólo ha considerado un cierto tipo de experiencia social muy limitada, por lo que las experiencias que surgen de las actividades asignadas a las mujeres, analizadas a través de la teoría feminista, pueden ser un punto de partida para desarrollar un conocimiento más completo y menos distorsionado que aquel que surge de las experiencias de los hombres. Las perspectivas de las mujeres son consideradas como un terreno mejor para la producción del conocimiento porque sus experiencias de exclusión y explotación son reconocidas como más inclusivas y críticas que las de los hombres (Hartsock, 1983; Smith, 1974; Rose, 1983). Al asumir que las mujeres tienen un privilegio epistemológico, las feministas que desarrollan la epistemología del posicionamiento no reconocen que las relaciones de dominación pueden afectar el conocimiento de la realidad que tienen los grupos oprimidos y parten de la premisa de que se trata de individuos racionales que siempre actúan en su propio beneficio. A pesar de que esta perspectiva rompe con algunas de las premisas epistemológicas de la Ilustración al develar las redes de poder que se ocultan tras el conocimiento científico, sigue reproduciendo la preocupación por la producción de un conocimiento universal y por lo menos generalizable para "las mujeres". Las diferencias de clase, raza, sexualidad o cultura son pasadas por alto al asumir la existencia de una experiencia femenina, que permite tener un punto de vista feminista. ${ }^{8}$

Las teóricas feministas, tanto las empiricistas como las promotoras de la epistemología del posicionamiento, se vieron en la necesidad de revisar sus teorías generalizadoras sobre el origen de la opresión de las mujeres, unas porque no lograban la esperada legitimación de la "ciencia", a pesar de que utilizaban las mismas herramientas sancionadas por los cánones del conocimiento científico, y las otras porque sus metanarrativas empezaron a ser puestas en duda desde la práctica política de feministas negras, chicanas e indias, entre otras. Estos feminismos

${ }^{8}$ Para una crítica más desarrollada al stand point theory véase Di Stefano, 1990, y Flax, 1990. no hegemónicos señalaron que muchos de los discursos feministas académicos reproducían el mismo problema de los metadiscursos modernistas al plantear la experiencia de las mujeres occidentales, blancas, de clase media como la experiencia de las mujeres en general, con una perspectiva etnocentrista y heterosexista (Alarcón, 1990; Alexander y Mohanty, 1997; Mohanty, 1991; Trinh, 1978).

Estas metanarrativas no sólo no promovían la "hermandad" sino que al excluir las experiencias de otras mujeres debilitaban la lucha y al centrar toda su atención en el género como el principal eje de dominación no creaban las condiciones para establecer otro tipo de alianzas políticas. En respuesta a estas críticas es que surge una tendencia a teorizar desde perspectivas feministas que reconozcan las diferencias culturales e históricas.

\section{FEMINISMOSY POSMODERNISMOS. COINCIDENCIASY RESISTENCIAS}

Para las feministas, la revelación hecha por los teóricos posmodernos de que el conocimiento científico oculta tras su discurso de objetividad y neutralidad visiones parciales de la realidad que legitiman relaciones de dominación no es algo nuevo, es algo que muchas de ellas estaban viviendo y diciendo desde diferentes perspectivas. Sus señalamientos no han sido sólo con respecto a las ciencias sociales, disciplina en la que existen muchos antecedentes a las críticas posmodernas — que van desde los análisis marxistas de la escuela de Frankfurt hasta la antropología crítica poscolonial (Asad, 1973; Leclercq, 1972)—, sino también con respecto a otras áreas del conocimiento científico. La manera en que la biología ha contribuido a naturalizar las desigualdades entre los géneros ha sido analizada por varias investigadoras feministas (Bleir, 1984; Harding, 1986; Hubbard, Henifin y Fried (eds), 1982); otras han develado la forma en que los primatólogos han interpretado el comportamiento animal a partir de sus perspectivas de género (Haraway, 1991) o en que los arqueólogos han reconstruido el pasado e interpretado los restos materiales desde sus propias visiones de los espacios y actividades asignadas a hombres y mujeres (Conkey y Williams, 1991). En el campo de la tecnología hay 
análisis que nos muestran la manera en que el mundo de la computación (Weizebaum, 1976) o la investigación sobre vida e inteligencia artificial (Helmreich, 1998) han estado determinados por las perspectivas de clase, género y raza de los investigadores.

Las feministas tenían pues un largo camino recorrido cuando Michel Foucault deconstruyó magistralmente la manera en que el conocimiento médico había sido utilizado para disciplinar los cuerpos (1992), o cuando Lyotard señaló que "la ciencia no se reduce a enunciar regularidades útiles y buscar lo verdadero, sino que debe legitimar sus propias reglas de juego" (Lyotard, 1990 [1984]). De hecho, muchas feministas consideran que el análisis de género, como herramienta de deconstrucción, es una de las principales aportaciones del feminismo al posmodernismo (aunque este aporte no sea reconocido por los teóricos posmodernos).

Las coincidencias en las críticas a la filosofía y a la ciencia occidental entre feministas y teóricos posmodernos ha influido en que algunas analistas propongan la construcción de un nuevo feminismo posmoderno que recupere pensamiento, llenando los vacíos que ambas aproximaciones tienen. Nancy Fraser y Linda Nicholson (1990) proponen que ambas perspectivas se pueden complementar, el posmodernismo puede aportar a un feminismo antiesencialista y el feminismo a un posmodernismo socialmente crítico: "Una reflexión posmoderna en la teoría feminista nos permitiría develar los inútiles vestigios del esencialismo, mientras que una reflexión feminista en el posmodernismo revelaría su androcentrismo e ingenuidad política” (p. 20).

Las preocupaciones prácticas del feminismo han hecho que se tome con reservas el impulso relativista del posmodernismo y que la utopía feminista (herencia de la modernidad) siga siendo el horizonte político hacia el que se orientan la producción teórica y la práctica política. De ahí que Sandra Harding señale que "en este momento histórico, nuestro feminismo necesita tanto de valores de la Ilustración como del posmodernismo, pero no necesitamos ni los mismos, ni por las mismas razones, ni en la misma forma que lo necesitan los hombres blancos occidentales y androcéntricos" (1990: 100).
Quienes han optado por autodefinirse como feministas posmodernas lo han hecho deslindándose del relativismo extremo y de la pasividad política del posmodernismo hegemónico y andocéntrico. Una de las diferencias entre las feministas y los posmodernistas como Lyotard y Rorty, es que estos últimos han desechado cualquier epistemología por considerar que una teoría del conocimiento sólo sirve para racionalizar y legitimar las creencias de los poderosos. Sin embargo, las feministas, ante el contexto de dominación que enfrentan, necesitan de estas epistemologías para defenderse tanto del objetivismo como del relativismo o interpretacionismo. El objetivismo parte de la premisa de que el conocimiento científico sólo se puede producir desde una perspectiva neutral, libre de valores e intereses, por lo que la investigación desarrollada desde una perspectiva feminista nunca llenará los "requisitos" de la ciencia. Pero en el otro extremo, el interpretacionismo o relativismo ve la interpretación de las feministas sobre el mundo como una opinión más, igual de defendible que las posturas patriarcales. Ante esta disyuntiva Harding señala que "la investigación feminista puede tener como propósito el producir representaciones menos perversas y parciales de la realidad, sin tener necesariamente que afirmar el valor absoluto, completo, universal o eterno de estas representaciones" (1990: 100).

Otra diferencia importante respecto a la propuesta de Lyotard (op. cit.) es que las feministas no renuncian al análisis de las macroestructuras de dominación, pues sostienen que estas herramientas teóricas permiten ir más allá del análisis de los problemas locales. Sin embargo, advierten que estas teorías deben estar situadas históricamente y que deben responder a las especificidades culturales de diferentes sociedades y periodos (Fraser y Nicholson, 1990; Haraway, 1991; Flax, 1990; Harding, 1990). Proponen también que se realice una vigilancia epistemológica permanente que permita reconocer las genealogías de las categorías que utilizamos, contextualizándolas dentro de la narrativa histórica en la que se ubican (Butler, 1990, para el concepto de género;Young, 1990, para el concepto de comunidad; Fraser y Nicholson, 1990, para el concepto de posmodernismo). Un principio fundamental del feminismo posmoderno es el rechazo a los universalismos y las generalizaciones, ya que advierte que 
el propósito del análisis intercultural debe ser siempre comparativo y no emprenderse con el objetivo de encontrar constantes universales (Strathern, 1988). Pero el principal elemento que diferencia esta propuesta feminista del posmodernismo androcéntrico es que parte de la premisa de que la teoría es una herramienta para la práctica política. No obstante, esta práctica ya no asume la existencia de una identidad unificada y de intereses compartidos entre todas las mujeres, sino que surge del reconocimiento de la diversidad de experiencias y necesidades de las distintas mujeres, por lo que la organización colectiva debe fundamentarse en una política de alianzas (Anzaldúa, 1988; Haraway, op. cit., Fraser y Nicholson, 1990; Young, 1989, 2000). Las feministas posmodernas anteponen a la postura de permanente parcialidad una política de solidaridad que articule a sujetos fragmentados en sus diferentes luchas (Harding, 1986: 195-196).

Otras feministas han recibido con más reservas los aportes metodológicos que las feministas posmodernas han recuperado de los teóricos posestructuralistas. El hecho de que los principales teóricos del posmodernismo sean hombres blancos, burgueses, occidentales (Lyotard, Derrida, Foucault, Rorty), que han escrito y desconstruido la producción teórica de otros hombres con las mismas características - sin reconocer ni recuperar los aportes del feminismo a la crítica de la Ilustración y totalmente ciegos al análisis de género en sus arqueologías y genealogías del conocimiento - ha despertado, por principio, la desconfianza de muchas feministas con respecto a las posibilidades de un diálogo constructivo (Bordo, 1990; Di Leonardo, 1991; Di Stefano, 1990).

La propuesta de descentramiento del sujeto hecha por los posmodernistas es considerada por algunas como una estrategia más de dominación de la filosofía patriarcal: “¿Por qué precisamente en este momento de la historia occidental, cuando aquellas poblaciones antes silenciadas han empezado a hablar por ellas mismas y en nombre de sus subjetividades, es que se pone en duda el concepto de sujeto y la posibilidad de descubrir-crear una 'verdad' liberadora?" (Harstock, 1983: 97). Estas perspectivas anti-posmodernas consideran que la política feminista necesita la existencia de un sujeto, las mujeres, para articularse y que el rechazo posmoderno a cualquier teo-

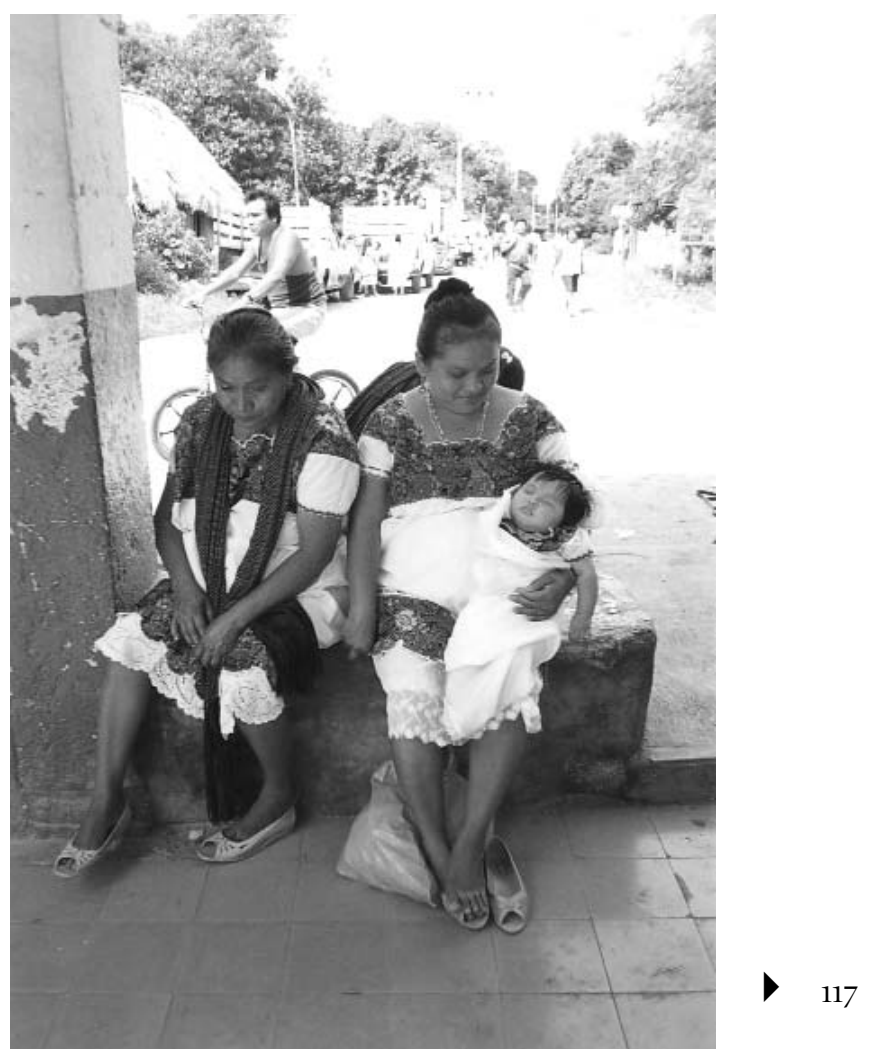

Mujeres de Huechenbalam, Tiholop, 2003 / Jesús Lizama.

ría o práctica centrada en el sujeto hace incompatible y peligrosa su propuesta para la práctica feminista.

Otra de las críticas a la propuesta de las feministas posmodernas tiene que ver con el debilitamiento político y heurístico que puede sufrir el concepto de género si se le deconstruye y relativiza: "Si el género ha provocado tanto escepticismo, puede suceder que consideren que es tiempo de renunciar a las estabilidades del concepto por una atención más radical y descentrada en diferencias múltiples, sin que ninguna de éstas amerite ser privilegiada teóricamente" (Di Stefano, 1990: 75).

Sin embargo, estos señalamientos derivan más de la desconfianza hacia el posmodernismo androcéntrico que de una reflexión profunda sobre las propuestas de las teóricas posmodernas que, como vimos, no proponen renunciar a la práctica feminista, sino replantearla a partir de una visión históricamente situada de las mujeres (siem- 
pre en plural) y de las relaciones de género. Por supuesto, que el reto de construir "solidaridades" y "alianzas" entre mujeres con distintas experiencias y necesidades es mucho más difícil que el asumir que todas compartimos la misma opresión y por lo tanto coincidimos con una agenda política establecida por unas pocas desde un espacio de poder.

\section{REFLEXIONES DESDE LOS MÁRGENES}

Pero, ¿es posible hablar de posmodernismo desde la posición en que reflexionamos y escribimos las feministas latinoamericanas? Y, ¿qué tan útiles son las propuestas epistemológicas de las feministas posmodernas para nuestros contextos culturales y políticos?

Mucho se ha debatido desde América Latina sobre la pertinencia del término posmodernismo para proyectos nacionales o formaciones sociales que ni siquiera han llegado plenamente a la modernidad o han vivido una modernidad incompleta y desigual (Osorio, 1989; Ducapitalista y de su lógica cultural propuestas por Jameson (1990) han sido fuertemente criticadas desde el contexto latinoamericano, pues si bien es cierto que el proyecto globalizador ha traído cambios importantes en los procesos de trabajo y ha convertido a nuestros países en economías maquiladoras, estos procesos no han implicado una homogeneización cultural ni mucho menos el surgimiento de un sujeto posmoderno enajenado como el descrito por el teórico de la posmodernidad (Beverly, Oviedo y Aronna, eds., 1995). Algunos autores señalan que la posmodernidad es precisamente la forma que ha tomado la modernidad desigual en América Latina (Brunner, 1995) o prefieren acuñar nuevos términos para referirse a la forma específica en que ha respondido nuestro continente a los retos de la globalización capitalista, como trans-modernidad (Dussel, 1995) o modernidad periférica (Brunner, op. cit.). Las nuevas tecnologías de la comunicación, el poder ideológico de los medios masivos, la fractura de los procesos productivos mediante la línea de ensamble global son una realidad en América Latina, pero las diversas respuestas que han dado los pueblos a

estos mecanismos de dominación han estado determinadas por el contexto cultural, la historia política y social de los mismos.

Sin embargo, desde diferentes espacios políticos se coincide con los teóricos posmodernos en que la modernidad como sistema cultural —que ha dejado fuera a una gran parte de la humanidad, incluyendo a las mujeres, y que ha construido un sistema de valores y poderes mediante la negación de todo aquello que no es masculino y occidental - está en crisis y debe de ser sustituida por algún tipo de proyecto alternativo. Las palabras de $\mathrm{Su}$ san Harding en el sentido de que "toda la racionalidad de la humanidad existente no se limita — ni tampoco está representada - por el Occidente moderno. Si otras instituciones prácticas para obtener el conocimiento han existido fuera del Occidente moderno, burgués y androcéntrico, ¿̨por qué las nuevas formas deseables de ciencia y conocimiento deben de restringirse a aquéllas dominantes en el Occidente?" (1990: 89) encuentran eco en muchas de las propuestas del movimiento indígena (Albó, 1995) y en las búsquedas de los distintos feminismos latinoamericanos (Hernández Castillo, 2001; Olea, 1995 y Tuñon, 1997).

Hay también elementos de las propuestas epistemológicas y políticas de las feministas posmodernas que podrían sernos útil para replantear nuestros propios feminismos y sus posibles alianzas políticas. La crítica desarrollada por las posestructuralistas y por las "feministas de color" (para utilizar un concepto de autodefinición) al feminismo académico anglosajón y europeo, en el sentido de que sus conceptos universalizantes y homogeneizadores de la opresión de la mujer no han reconocido las diferencias de clase, género, generación y preferencia sexual de muchas mujeres, silenciando sus voces y negando sus experiencias, bien puede aplicarse a mucho del feminismo académico hegemónico en América Latina.

En otros trabajos he analizado el caso específico del feminismo mexicano (Hernández Castillo, op. cit.), señalando que a pesar de que desde la década de 1980 incorporó a sus definiciones de género la diversidad de contextos en que éste se construye, reconociendo que "La asimetría entre hombres y mujeres significa cosas distintas en lugares diferentes. Por lo mismo la posición de las mujeres, 
sus actividades, sus limitaciones y sus posibilidades varían de cultura en cultura" (Lamas, 1986: 184), este reconocimiento no conllevó a una agenda feminista incluyente que diera cuenta de las necesidades específicas que tienen las mujeres indígenas. Bajo la influencia del feminismo liberal estadounidense y europeo, la agenda del movimiento feminista mexicano ha estado marcada por las demandas de maternidad voluntaria y reconocimiento a los derechos reproductivos, la lucha contra la violencia sexual y doméstica y por los derechos de homosexuales y lesbianas (Tuñon, 1987 y Marcos, 2000). Aunque algunas de estas demandas son compartidas por mujeres indígenas — sobre todo en lo que respecta a derechos reproductivos y la lucha contra la violencia- no reflejan sus principales preocupaciones, que han girado en torno a demandas económicas y culturales, producto de las experiencias de racismo y explotación que han configurado sus identidades genéricas. En este sentido, podríamos aplicar al etnocentrismo del feminismo hegemónico en México la misma crítica que Judith Butler plantea a la homofobia del feminismo académico estadounidense al señalar que "cualquier teoría feminista que restrinja el significado del género en las presuposiciones de su propia práctica establece normas de género excluyentes en el seno del feminismo, a menudo con consecuencias homofóbicas [en nuestro caso etnocéntricas]" (Butler, 2001: 9).

Este etnocentrismo se ha puesto en evidencia sobre todo a partir del surgimiento de un incipiente movimiento feminista indígena que ha comenzado a poner en duda las visiones esencialistas del feminismo y del movimiento indígena nacional. Podríamos decir que ha descentrado al sujeto histórico del feminismo, señalando la diversidad de experiencias que excluyó esa construcción teórica y política. ${ }^{9}$

Se trata de un grupo aún minoritario de mujeres indígenas, procedentes de diversas regiones del país y con distintas historias organizativas, que han venido articulando sus luchas a partir del levantamiento zapatista —iniciado el $1^{\circ}$ de enero de 1994- con una agenda política en la

${ }^{9}$ Para una descripción más detallada del movimiento de mujeres indígenas en México y del caso específico de la Coordinadora Nacional de Mujeres Indígenas, véase Artía, 2001, y Hernández Castillo, op. cit. que combinan sus demandas específicas de género con las autonómicas de sus pueblos. Es, por lo tanto, una lucha en muchos frentes. Por un lado, las mujeres indígenas organizadas han unido sus voces al movimiento indígena nacional para denunciar la opresión económica y el racismo que marca la inserción de los pueblos indios en el proyecto nacional. Paralelamente, estas mujeres están desarrollando un discurso y una práctica política propia a partir de una perspectiva de género situada culturalmente que viene a cuestionar tanto el sexismo y el esencialismo de las organizaciones indígenas como el etnocentrismo del feminismo hegemónico. ${ }^{10}$

El contexto económico y cultural en el que las mujeres indígenas han construido sus identidades de género marca las formas específicas que toman sus luchas, sus concepciones sobre la "dignidad de la mujer" y sus maneras de plantear alianzas políticas. Las identidades étnicas, clasistas y de género han determinado las estrategias de lucha de estas mujeres, que han optado por incorporarse a las luchas más amplias de sus pueblos, pero a la vez han creado espacios específicos de reflexión sobre sus experiencias de exclusión como mujeres y como indígenas. Parecería pues un ejemplo de politica de solidaridad, construida a partir de alianzas que articulan a los diferentes.

Las mujeres indígenas han mantenido una doble militancia, vinculando sus luchas específicas de género a las luchas por la autonomía de sus pueblos. Esta doble militancia, sin embargo, ha tenido que enfrentar muchas resistencias, tanto por parte del movimiento feminista como del indígena. Consideramos que ambos movimientos se han visto beneficiados por esta doble militancia: las feministas al verse estimuladas a tomar en cuenta la diversidad

\footnotetext{
${ }^{10}$ Utilizo el término de feminismo hegemónico para referirme al feminismo surgido en el centro del país y teorizado desde la academia, en el que la lucha contra el aborto y por los derechos reproductivos ha sido central. Desde la formación de la Coalición de Mujeres Feministas en 1976 y posteriormente con la creación del Frente Nacional por la Liberación y los Derechos de las Mujeres (FNALIDM) en 1979, la despenalización del aborto y la lucha contra la violencia doméstica fueron las demandas aglutinadoras de este feminismo. Él mismo era hegemónico frente a otros feminismos populares y rurales en los cuales las demandas de clase se vinculaban estrechamente a las demandas de género. Para una historia del feminismo hegemónico, véase Tuñon, 1997. Para una historia del feminismo popular y el carácter clasista de sus demandas, véase Masolo, 1992.
} 
cultural en sus análisis de la desigualdad de género y el movimiento indígena al tener que incorporar el género a sus perspectivas sobre la desigualdad étnica y clasista que viven los pueblos indios.

Sin pretender imponer en las mujeres indígenas la identidad de sujetos posmodernos - colonizando nuevamente sus representaciones-, sí considero que su política de alianzas y sus cuestionamientos a los discursos esencialistas del movimiento indígena y del movimiento feminista aportan elementos para renovar nuestros imaginarios políticos y construir un nuevo feminismo multicultural que confronte los discursos totalizadores de la modernidad occidental.

\section{Bibliografía}

Alexander, Jacqui y Chandra Talpade Mohanty, 1997, Feminist Genealogies, Colonial Legacies and Democratic Futures, Routledge Press, Nueva York y Londres.

Alarcón, Norma, 1990, "The Theoretical Subjects of This Bridge Called My Back and Anglo-American Feminism", en Gloria Anzaldúa (ed.), Making Faces/Making Soul: Haciendo caras, Editorial Aunt Lute, San Francisco, pp. 40-68.

Albó Xavier, 1995, "Our Identity Starting from Pluralism in the Base" en Beverly John, José Oviedo y Michael Aronna (eds.), The Postmodern Debate in Latin America, Duke University Press, Durham y Londres, pp. 18-34.

Artía Rodríguez, Patricia, 2001, Desatar las voces, construir las utopias: la Coordinadora Nacional de Mujeres Indígenas en Oaxaca, tesis de maestría en antropología social, CIESAS, México.

Anzaldúa, Gloria, 1987, Bordelands/La Frontera: The New Mestiza, Spiters-Aunt Lute, San Francisco, California.

Asad, Talal, 1973, Anthropology and the Colonial Encounter, Ithaca Press, Londres.

Beverly John, José Oviedo y Michael Aronna (eds.), 1995, The Postmodern Debate in Latin America, Duke University Press, Durham y Londres.

Bleir, Ruth, 1984, Science and Gender: A Critique of Biology and its Themes on Women, Pergamon Press, Nueva York.

Bordo, Susan, 1990, "Feminism, Postmodernism and Gender-Scepticism", en L. Nicholson (ed.), Feminism/Posmodernism, Routledge Press, Nueva York y Londres, pp. 133-157.

Brunner, José Joaquín, 1995, "Notes on Modernity and Postmodernity in Latin American Culture", en John Beverly, José Oviedo y Michael Aronna (eds.), The Postmodern
Debate in Latin America, Duke University Press, Durham y Londres, pp. 34-55.

Butler, Judith, 2001, El género en disputa. El feminismo y la subversión de la identidad, Paidós/PUEG-UNAM, México.

Colquhoun A., 1985, On Modern and Postmodern Space, Princeton Architectural Press, Princeton.

Conkey, Margaret W. y Sarah H. Williams, 1991, “Original Narratives: The Political Economy of Gender in Archaeology" en Micaela di Leonardo (ed.), Gender at the Crossroads of Knowledge. Feminist Anthropology in the Postmodern Era, University of California Press, Berkeley, California, pp. 102-140.

Chodorow, N., 1978, The Reproduction of Mothering, University of California Press, Berkeley, California.

Di Lionardo, Micaela (ed.), 1991, Gender at the Crossroads of knowledge. Feminist Anthropology in the Postmodern Era, University of California Press, Berkeley, California.

Di Stefano, Christine, 1988, "Dilemmas of Difference: Feminism, Modernity and Postmodernism", Women and Politics, vol. 8, núm. 3/4, pp. 1-24.

Dussel, Enrique, 1995, "Eurocentrism and Modernity (Introduction to the Frankfurt Lectures)", en John Beverly, José Oviedo y Michael Aronna (eds.), The Postmodern Debate in Latin America, Duke University Press, Durham y Londres, pp. 65-77.

Einstein, H., y A. Jardine (eds.), 1980, The Future of Difference, G.K. Hall, Boston Mass.

Foucault, Michel, 1980, Power/Knowledge: Selected Interviews and Other Writings, Pantheon Press, Nueva York.

_ 1992, Historia de la sexualidad. La voluntad de saber, Siglo XXI, Madrid, España. , 1995, Vigilar y castigar, Siglo XXI, México.

Fraser, Nancy, y Linda Nicholson, 1990, "Social Criticism without Philosophy: An Encounter between Feminism and Posmodernism", en L. Nicholson (ed.), Feminism/ Posmodernism, Routledge Press, Nueva York y Londres, pp. 19-39.

Flax, Jane, 1990, "Postmodernism and Gender Relations in Feminist Theory", en L. Nicholson (ed.), Feminism/Posmodernism, Routledge Press, Nueva York y Londres, pp. 39-63.

Firestone, Shulamith, 1970, The Dialectic of Sex: The Case for Feminist Revolution, Bantam Books, Nueva York.

Haraway, Donna, 1990, "A Manifiesto for Cyborgs: Science, Technology and Socialist Feminism in the 1980's", en L. Nicholson (ed.), Feminism/Posmodernism, Routledge Press, Nueva York y Londres, pp. 190-234.

—, 1991, Simians, Cyborgs and Women. The Reinvention of Nature, United Kingdom Free Association Books LTD, Londres.

Harding, Sandra, 1986, The Science Question in Feminism, Cornell University Press, Ithaca, Nueva York. 
_ 1990, "Feminism, Science and the Anti-Enlightment Critiques", en L. Nicholson (ed.), Feminism/Posmodernism, Routledge Press, Nueva York y Londres, pp. 83-107.

Hartsock, N., 1983, Money, Sex and Power. Toward a Feminist Historical Materialism, Longman, Nueva York y Londres.

Harvey, David, 1989, The Condition of Postmodernity, Blackwell Press, Cambridge Mass.

Helmreich, Stephan, 1998, Silicon Second Nature, University of California Press, Los Angeles, California.

Hernández Castillo, Rosalva Aída, 1994, "Fredic Jameson: de la crítica literaria al análisis cultural del capitalismo tardío", Iztapalapa, Universidad Autónoma Metropolitana, vol. 14, núm. 33, pp. 129-155.

_ 2001, "Entre el etnocentrismo feminista y el esencialismo étnico. Las mujeres indígenas y sus demandas de género", Debate Feminista, año 12, vol. 24, octubre, pp. 206-230.

Hook, Bell, 1988, Talking Back, Thinking Feminisit, Thinking Black, South End Press, Boston, Mass.

Hubbard, Ruth, Marie Sue Henifin y Barbara Fied (eds), 1982, Biological Woman. The Convenient Myth, Schenkman Press, Cambridge Mass.

Jameson, Frederic, 1990, Posmodernism or the Cultural Logic of Late Capitalism, Duke University Press, Durham.

Kannabiran, Vasanth, 1997, "Looking at Ourselves: The Women's Movement in Hyverabad", en Jacqui Alexander y Chandra Talpade Mohanty, Feminist Genealogies, Colonial Legacies and Democratic Futures, Routledge Press, Nueva York y Londres, pp. 259-280.

Lamas, Marta, 1986, "La antropología feminista y la categoría de género”, Nueva Antropología, vol. VIII, núm. 30, pp. 173-222.

Larsen, Neil, 1995, "Posmodernism and Imperialism in Latin America", en John Beverly, José Oviedo y Michael Aronna (eds.), The Postmodern Debate in Latin America, Duke University Press, Durham y Londres, pp. 110-135.

Leclercq, Gerard, 1972, Antropología y colonialismo, Editorial THF, Medellín, Colombia.

Lyotard, Jean-François, 1993 [1984], La condición posmoder$n a$, Red Editorial Iberoamericana, México.

— y Jean Loup Thebaud, 1987, Just Gaming, University of Minnessota Press, Mineapolis.

Mamma, Amina, 1995, "Sheroes and Villains: Conceptualizing Colonial and Contemporary Violence Against Women in Africa", en Jacqui Alexander y Chandra Talpade Mohanty, Feminist Genealogies, Colonial Legacies and Democratic Futures, Routledge Press, Nueva York y Londres, pp. 46-63.

Mani, Lata, 1999, "Tradiciones en discordia: el debate sobre el sati en la India colonial", en Saurabh Dube (coord.), Pasados poscoloniales, El Colegio de México, México, pp. 209-253.
Marcos, Sylvia, 1999, "Twenty five Years of Mexican Feminisms”, Women's Studies International Forum, vol. 22, núm. 4, pp. 431-433.

Mohanty, Chandra, 1991, "Under Western Eyes: Feminist Scolarship and Colonial Disccourses", en Chandra Mohanty, Ann Russo y Lourdes Torres (eds.), Third World Women and the Politics of Feminism, Indiana University Press, Broomington, pp. 51-81.

Moya, Paula M., 1997, "Postmodernism, Realism and the Politics of Identity: Cherry Moraga and Chicana Feminism", en Jacqui Alexander y Chandra Talpade Mohanty, Feminist Genealogies, Colonial Legacies and Democratic Futures, Routledge Press, Nueva York y Londres, pp. 125-151.

Nicholson, Linda J. (ed.), 1990, Feminism/Posmodernism, Routledge Press, Nueva York y Londres.

Olea, Raquel, 1991, "El feminismo: ¿moderno o posmoderno?", Mujeres en Acción, invierno, Santiago de Chile, pp. 7-16.

Osorio, Nelson, 1989, "Debate sobre posmodernismo", Revista de Crítica Literaria Latinoamericana, núm. 29, pp. 146-148.

Rortry, R., 1979, Philosophy and the Mirror of Nature, Princeton University Press, Princeton.

Rose, Hilary, 1983, "Heart, Brain and Heart: A Feminist Epistemology for the Natural Science", Signs Journal of Women Culture and Society, vol. 1, núm. 9, pp. 73-90.

Rosaldo, Michelle Zimbalist, 1974, "Woman, Culture and Society: A Theoretical Overview", en Michele Z. Rosaldo y Louise Lamphere (eds.), Women, Culture and Society, Stanford University Press, Stanford, pp. 20-38.

Said, Edward, 1987, "Postmodernism, Practice, Politics, Performance", ponencia presentada en el Whitney Humanities Center, Universidad de Yale, 21 de febrero.

Smith, Dorothy, 1974, "Women's Perspective as a Radical Critique of Sociology", Sociological Inquiry, núm. 44, pp. 7-13.

Strathern, Marilyn, 1988, The Gender of the Gift: Problems with Women and Problems with Society in Melanesia, University of California Press, Berkeley.

Trinh, Min-ha, 1998, Woman, Native, Other: Writing Postcoloniality and Feminism, Indiana University Press, Indiana.

Tuñón, Esperanza, 1997, Mujeres en escena: de la tramoya al protagonismo (1982-1994), Programa Universitario de Estudios de Género, PUEG-UNAM, México.

Weizebaum, Joseph, 1976, Computer Power and Human Reason, Freeman Press, San Francisco, California.

Young, Iris Marion, 1989, "Polity and Group Difference: A Critique of the Ideal of Universal Citizenship", Ethics, núm. 99, pp. 250-274.

- 2000, La justicia y la política de la diferencia, trad. de Silviana Álvarez, Ediciones Cátedra, Valencia. 